\title{
Narrativas de mulheres e da lesbianidade: discursos do "outrolugar"
}

Isadora Araújo Pontes*

Resumo: O objetivo deste trabalho é discutir a literatura escrita por mulheres de modo descentrado ao atribuído culturalmente ao feminino e à própria noção de mulher, que supõe, compulsoriamente, também a heterossexualidade. A leitura proposta tem como basilar o conceito de "outro lugar" (DE LAURETIS, 1994) para se pensar os discursos que habitam espaços dentro e fora da cultura dominante, o "ponto cego" implícito mas invisível, numa posição de contradição e resistência capaz de (re)construir e (re)inscrever o gênero. Inicialmente, busco demonstrar porque é aqui tensionada a noção de feminino, optando-se por pensar a literatura escrita por mulheres e sobre a lesbianidade como um discurso que provém desse espaço alternativo, das brechas do discurso hegemônico, ameaçando sua estabilidade. Em seguida, a obra Thérèse et Isabelle (2000) de Violette Leduc é aqui analisada para se pensar como esse discurso, cujo tema é não apenas uma experiência da mulher, mas a relação entre duas moças, se articula em um texto que explora o corpo desejante em sua pluralidade. Tal obra é apontada como pertencente ao "continuum lésbico" pensado por Adrienne Rich (2010), cuja própria existência já representa uma forma de ruptura do discurso hegemônico através das fendas que vão irrompendo dentro dele mesmo.

Palavras-chave: Escrita de mulheres; Estudos de gênero; Lesbianidade; Violette Leduc.

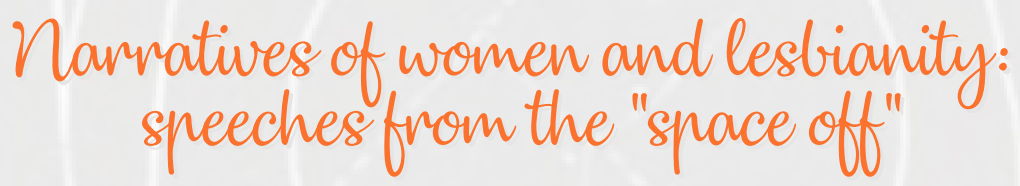

Abstract: The aim of this work is to discuss the literature written by women in a decentralized way to what is culturally attributed to the feminine and the very notion of woman, which also compulsorily supposes heterosexuality. The critical reading proposed has the basic concept of "space off" (DE LAURETIS, 1994) to think the speeches that inhabit spaces inside and outside the dominant culture, the "blind spot" implicit but invisible in a position of contradiction and resistance capable of (re)constructing and (re)inscripting the gender. Initially, I seek to demonstrate why the notion of feminine is here problematized, opting for thinking literature written by women and about lesbianity as a discourse that comes from this alternative space, from the breaches of the hegemonic discourse, threatening its stability. Then the work Thérèse et Isabelle (2000) by Violette Leduc is here analyzed to think about the possibilities in the literature of a discourse, whose theme is not only an experience of women, but the relationship between two girls, articulated in a text that explores the desiring body in its plurality. Such work is identified as belonging to the "lesbian continuum" thought by Adrienne Rich (2010), whose very existence is a way to break the hegemonic discourse through the fissures breaking out inside the discourse itself.

Keywords: Women's writting; Gender studies; Lesbianity; Violette Leduc.

* Doutoranda em Literatura comparada pela Universidade Federal Fluminense.

Contato: pontes.isadora@yahoo.com 


\section{Resistência é um grande tema no presente ensaio \\ e no próprio estudos da vida das mulheres, \\ se sabemos o que estamos procurando. \\ Adrienne Rich}

Dentre as discussões que compõem os estudos de literatura preocupados com questões relacionadas à produção de mulheres, a que se faz mais controversa, apresentando argumentos com diferentes nuances, diz respeito à terminologia e à possibilidade de se pensar um campo específico dentro do grande campo da literatura a ser designado por nomes como "escrita feminina" e "literatura feminina". A questão da nomenclatura gera um debate sobre quais textos estariam sob esta insígnia ou mesmo o que os conceitos mobilizados, feminino ou feminina, designariam, e se seriam referidos aos leitores ou somente às autoras.

Mesmo se considerarmos o termo "feminino" apenas enquanto um qualitativo do texto que significa "ter sido escrito por uma mulher", fica ainda a questão dos desdobramentos da significação desse feminino e em que medida esta não seria uma volta a um essencialismo, pois é perigoso assumir uma postura universalista e dizer que o simples fato de um livro ter sido escrito por uma mulher the confere invariavelmente certas especificidades. Buscando no dicionário Aurélio pelo termo "feminino", temos as seguintes definições: "próprio de mulher", "que é do gênero feminino", "gênero feminino: gênero das palavras que indicam fêmea ou das que se consideram não masculinas". À vista dessas definições, pensar no feminino, parece estar atrelado a pensar em algo "próprio" a um determinado grupo de indivíduos encaixados dentro da categoria "mulher", construída em oposição ao "masculino". Porém, ainda que seja importante considerar tais conceitos como menos estáticos, também não podemos esquecer como os aparatos de produção e controle dos corpos os definem e os estilizam, de modo que apesar de a noção de um "próprio" remeter a uma origem e mesmo a uma essência contestáveis, não se deve ignorar que os sujeitos marcados pelo feminino possuem vivências específicas que podem ser manifestadas pela escrita, sobretudo na escrita referencial.

Levando em conta essas problemáticas, mas sem procurar respondê-las, apenas pensando com elas, proponho um olhar para a escrita das mulheres e da lesbianidade centrado na obra Thérèse et Isabelle, de Violette Leduc, publicada oficialmente em 1966, buscando pensar como essa e outras escritas podem ser situadas enquanto oriundas de "outro lugar", alternativo ao discurso dominante. A obra a ser abordada representa uma voz, em certo sentido, pioneira na literatura homossexual escrita por mulheres, principalmente devido ao modo como o corpo figura. Sendo assim, este trabalho tem como objetivo analisar a produção literária da mulher enquanto a escrita de um outro espaço que desafia as noções estáticas, agindo como um contra-discurso. A noção de "outro lugar" aqui mobilizada parte do ensaio "Tecnologias do gênero" de Teresa de Lauretis (1994) que convida as produções culturais feministas a definirem diferentemente os termos da construção social do gênero, partindo do ponto cego do discurso dominante, um espaço implícito das margens do sistema de gênero, numa posição de constante tensão. O qualitativo "feminista" é empregado com o intuito de designar uma produção que não pode ser dissociada plenamente do político, no momento em que coloca em cena corpos e corporalidades 
marginalizados. Para tal, proponho duas etapas de reflexão, a primeira voltada para como podemos articular a passagem do feminino ao feminista e suas relações com a representação da sexualidade, determinando o que considero aqui como sistema de gênero e sujeito do feminismo; e, após essa delimitação teórica, uma segunda que abordará o diálogo dessas noções com a obra de Violette Leduc e como ela propõe, já no início da segunda metade do século XX, novas formas de pensar as relações.

\section{Dofeminino a feminista}

Frequentemente, temos acesso a entrevistas e discursos em que as mulheres escritoras se colocam em desacordo com a noção de uma "literatura feminina", a exemplo de Nelida Piñon (2017), que diz detestar o termo e justifica: "Você não fala em literatura masculina; você fala em literatura, e de preferência boa literatura". Tal colocação merece destaque pois demonstra como o tido como desviante em relação ao universal é sempre o feminino, já que não se questiona os autores homens sobre a escrita de uma "literatura masculina", inscrevendo, desse modo, a produção deles no que é literatura como um todo. Pierre Bourdieu (2014) aponta como o dominante é considerado enquanto neutro e universal e o dominado como o elemento marcado. Essa visão revela uma dupla problemática, pois marcar apenas o feminino significa reproduzir a noção de que o masculino condiz com o universal, porém a ausência de marcações também subtende o masculino no imaginário - a exemplo da tendência de se supor primeiramente que o narrador é masculino, a não ser que seu gênero seja explicitado.

Em A dominação masculina, de 1998, são apontados os processos pelos quais se dá a transformação do arbitrário cultural em natural nas relações de gênero. $\mathrm{O}$ sociólogo busca reinserir na história a divisão sexual, apontando como a percepção do mundo se articula a partir da oposição masculino/feminino que se insere num sistema de oposições homólogas, tais como: alto/baixo, seco/úmido, duro/mole, claro/escuro, público/privado etc. Segundo ele,

Esses esquemas de pensamento, de aplicação universal, registram como diferenças de natureza, inscritas na objetividade, os distanciamentos e os traços distintivos (em matéria corporal, por exemplo) que eles contribuem para que existam ao mesmo tempo que "naturalizam" ao inscrevê-los em um sistema de diferenças, todas igualmente naturais na aparência; de modo que as antecipações que engendram são incessantemente confirmadas pelo curso do mundo, por todos os ciclos biológicos e cósmicos especialmente. Também não se vê como poderia emergir na consciência a relação social de dominação que está em seu princípio e que, por uma inversão completa das causas e efeitos, aparece como uma aplicação em meio a outras de um sistema de relações de sentido perfeitamente independente das relações de força. (BOURDIEU, 2014, p. 20-21) 
Assim, a ordem social ratifica as dominações através desse processo de inversão das causas e efeitos, de modo que é essa mesma ordem que constrói o corpo enquanto uma realidade sexuada e não o contrário. Esse trabalho de construção simbólica legitimado por uma inscrição biológica se solidifica através de transformações duráveis dos corpos,

em e para um trabalho de construção prática que impõe uma definição diferenciada dos usos legítimos do corpo, principalmente sexuais, que tende a excluir do universo do pensável e do fazível tudo que marca um pertencimento a outro gênero - e em particular todas as virtualidades biologicamente inscritas no "perverso polimorfo" que é, a acreditar em Freud, toda jovem criança - para produzir esse artefato social que é o homem viril ou a mulher feminina. (BOURDIEU, 2014, p. 40)

O sucesso dessas trocas entre homens e mulheres que produzem e reproduzem os corpos socialmente, numa relação hierarquizada, depende daquilo que Bourdieu denomina "violência simbólica". Tal forma de violência se realiza de forma tácita, através de uma dominação que o dominado não tem meios para deixar de assentir, pois ele se pensa a partir dos próprios instrumentos de conhecimento que possui em comum com o dominante, o que passa a ideia de naturalidade. O efeito dessa dominação "se exerce não em uma lógica pura de consciências cientes, mas através de esquemas de percepção, de apreciação e de ação que são constitutivos dos habitus" (BOURDIEU, 2014, p. 58-59). A partir dessa visão, não seria possível suspender a dominação através apenas da tomada de consciência, pois os seus efeitos estão inscritos no próprio corpo como suas disposições, que no caso da mulher marcam o feminino pelo qual é definida. Apesar de não considerada por Bourdieu, não deve ser esquecida a capacidade do sujeito de agenciar suas próprias vivências, pois, mesmo que essa dominação não possa ser plenamente suspensa, a resistência e ação na construção da própria subjetividade e na subversão social são também possíveis.

Bourdieu critica, igualmente, a noção de algumas correntes do feminismo que tratam da "experiência feminina", aproximando de um pensamento essencialista e, por isso, a-histórico das relações. Segundo ele, para se escapar do essencialismo é necessário não a negação das permanências que compõe a realidade histórica, mas "reconstruir a história do trabalho histórico de des-historização" (BOURDIEU, 2014, p. 115), ou seja, pensar como se dá a recriação contínua das estruturas da dominação masculina, através de agentes como a Igreja, o Estado e a Escola. A partir dessas noções, é possível observar como os próprios termos nos quais se estabelecem as noções de feminino e feminilidade são oriundos de disposições hierarquizantes, que, através da inversão dos efeitos e das causas, chega-se na ideia de que as permanências observáveis ao longo da história seriam fruto de uma condição natural de separação e subjugação das mulheres pelos homens e não o produto de uma construção. Na linha dessa crítica às naturalizações que ignoram ou negligenciam a ação da história nos corpos, Teresa de Lauretis, em artigo publicado originalmente em 1987, levanta os problemas relacionados à noção de gênero enquanto diferença sexual, central para a produção feminista e cultural das décadas de 1960 e 70 . 
O conceito clássico de gênero foi formado a partir da oposição do pensamento ocidental entre natureza e cultura. Sendo assim, como aponta Strey (1998), o sexo seria biológico e reprodutivo, enquanto o gênero um sistema de características psicológicas e culturais que marcam as diferenças - já apontadas pelo sexo - entre homens e mulheres. Essa noção já está presente em $O$ Segundo Sexo, publicado em 1949, de Simone de Beauvoir, na famosa frase: "não se nasce mulher, torna-se mulher" (BEAUVOIR, 2014, p. 13). Na obra, Beauvoir constrói um pensamento da mulher enquanto o "Outro", que teria toda sua formação voltada para a compreensão de si como inessencial, enquanto o homem seria o "Um", o universal. Muitas teóricas feministas escreveram, igualmente, a partir dessa oposição. Monique Wittig (1976), no entanto, defende que designar a diferença de sexo é também criá-la, de modo que homens e mulheres seriam categorias políticas e não naturais.

A partir de meados da década de 1980, teóricas feministas que se aproximam, em certa medida, do pensamento de Wittig, como De Lauretis, passam a criticar o binarismo dessa visão polarizada. Segundo ela, a definição calcada na diferença sexual e os conceitos derivados marcados pelo gênero - tais como a "cultura da mulher", a "feminilidade" e a "escrita feminina" acabam agindo enquanto uma forma de limitação e deficiência do pensamento feminista, pois pensar em termos da diferença sexual significa, igualmente, pensar na diferença entre o homem e a mulher, entre o feminino e o masculino, o que, dentro da lógica do patriarcado ocidental, tratase de uma diferença em relação ao homem - que é o universal:

A primeira limitação do conceito de "diferença(s) sexual(ais)", portanto, é que ele confina o pensamento crítico feminista ao arcabouço conceitual de uma oposição universal do sexo (a mulher como a diferença do homem, com ambos universalizados: ou a mulher como diferença pura e simples e, portanto, igualmente universalizada), o que torna muito difícil, se não impossível, articular as diferenças entre mulheres e Mulher, isto é, as diferenças dentre as mulheres ou, talvez mais exatamente, as diferenças nas mulheres. (DE LAURETIS, 1994, p. 207)

Na crítica, é possível perceber que o problema da diferença sexual está no que ela exclui, que são as mulheres não compreendidas por essa visão universalizada. Nessa exclusão, é desconsiderada a constituição múltipla do sujeito que se dá para além da diferença sexual, sendo marcado também pelas experiências das relações de raça e classe. Como uma alternativa à noção de gênero tão presa à diferença sexual, propõe uma concepção pensada a partir da noção de Foucault sobre a sexualidade como "tecnologia sexual", que aplicada ao gênero permite que o pensemos enquanto (auto)representação, sendo mais o produto de tecnologias sociais do que uma propriedade de corpos ou algo existente a priori.

Ao pensar o gênero enquanto uma representação, chega-se em sua dimensão relacional, pois o gênero é a representação de uma relação que se dá a partir de um pertencimento a uma categoria. O gênero não se refere, desse modo, a um indivíduo separado dos outros, mas à construção de seu pertencimento a uma categoria que é necessária para inteligibilidade do sujeito - o que pode 
ser observado, por exemplo, no momento da descoberta do sexo do bebê, crucial para a escolha do nome, uma das principais marcas da inteligibilidade da pessoa enquanto indivíduo separado dos outros. A concepção de que o sujeito precisa ser compreendido dentro de um dos polos culturais, masculino ou feminino, forma o "sistema de gênero, um sistema simbólico ou um sistema de significações que relaciona o sexo a conteúdos culturais de acordo com valores e hierarquias sociais" (DE LAURETIS, 1994, p. 211).

Outra contribuição de De Lauretis está na associação da definição de gênero com a de ideologia de Althusser - a qual destaca a existência de um sujeito concreto sobre o qual a ideologia deve agir, construindo suas relações imaginárias. Assim, a "ideologia de gênero" seria sua função de "construir indivíduos concretos em homens e mulheres" (DE LAURETIS, 1994, p. 213), operação que se inscreve também no sistema das relações produtivas, a exemplo do trabalho. Considerando-se essa associação, é possível pensar que no sistema de gênero tanto sua representação social afeta sua construção subjetiva, quanto a representação subjetiva afeta sua construção social. Desse modo, De Lauretis desloca a noção de sujeito como apenas produto da construção social, apontando a possibilidade de agenciamento e autodeterminação, o que leva a afirmar que "a construção do gênero é o produto e o processo tanto da representação quanto da auto-representação" (DE LAURETIS, 1994, p. 217). O conceito de agência ou agenciamento é compreendido por Patricia Mann como um termo que "se refere a ações individuais ou em grupo consideradas significativas dentro de um ambiente social ou institucional específico" (MANN, 1994, p. 14) ${ }^{1}$ e, segundo Sara Salih (2015), que se apoia no pensamento de Judith Butler, enquanto a possibilidade de subverter a lei para que ela volte contra si mesma com intenções políticas e radicais.

A possibilidade de agenciamento permite que pensemos em uma ambiguidade do gênero relacionada intimamente com a noção de poder proposta por Foucault na História da sexualidade I. Segundo ele, o poder teria também uma forma criativa, agindo enquanto uma multiplicidade de relações de força interiores aos outros tipos de relações. A percepção da forma produtiva do poder leva ao conceito de "tecnologia sexual", que destaca sua ação de maximização da vida e da sexualidade, produzindo-as e controlando-as, no lugar de uma hipótese meramente repressiva apesar de pensar a partir da noção de poder de Foucault, a teórica não deixa de ressaltar que é perigoso nos forcarmos apenas no aspecto produtivo do poder e esquecer sua ação violenta.

Um dos questionamentos de Teresa de Lauretis sobre a teoria de Foucault e de outros filósofos pós-estruturalistas, como Derrida e Deleuze, está no modo como ignoram e negam o gênero como componente de uma subjetividade de mulheres reais, existindo apenas como uma figura textual ou como um devir, o que é também ignorar toda a história de dominação e resistência do feminismo, conferindo às mulheres o status de "futuro da humanidade" apenas quando negam sua existência real. É como culminação dessa crítica que Teresa de Lauretis faz um apelo pela construção de uma produção de narrativas teóricas e culturais que tragam a visão de "outro lugar", alternativa às narrativas masculinas de gênero presas ao contrato heterossexual que são reproduzidas também por algumas feministas. Esse outro lugar não remete a um futuro utópico ou à volta a um passado mítico e matriarcal, a salvo dos conflitos de classe e raça, mas "o outro lugar do discurso aqui e agora, os pontos cegos, ou o space-off 2 de suas representações", seria um "espaço nas margens dos discursos hegemônicos, espaços sociais entalhados nos 
interstícios das instituições e nas fendas e brechas dos aparelhos de poder-conhecimento" (DE LAURETIS, 1994, p. 237). Esse espaço seria a zona do excesso do gênero, que se apresenta como um trauma produzido por aquilo que o sistema de gênero não pode completamente representar, onde De Lauretis situa o sujeito do feminismo. Enquanto um espaço de recalcamento menos mediado, ele representa uma constante ameaça que pode vir à tona e desestabilizar o sistema que o marginalizou. Tal sujeito aludido por De Lauretis se refere a uma compreensão diferente das noções de Mulher, ser singular da essência feminina, ou mulheres, sujeitos reais e históricos engendrados nas relações sociais, mas enquanto um sujeito em andamento, um sujeito "dentro e fora da ideologia do gênero" que carrega em si mesmo uma relação de multiplicidade e tensão, pois habita simultaneamente os dois espaços, estando em um movimento constante entre

o espaço discursivo (representado) das posições proporcionadas pelos discursos hegemônicos e o space-off, o outro lugar, desses discursos: esses outros espaços tanto sociais quanto discursivos, que existem, já que as práticas feministas os (re)construíram, nas margens (ou "nas entrelinhas", ou "ao revés"), dos discursos hegemônicos e nos interstícios das instituições, nas contrapráticas e novas formas de comunidade. (DE LAURETIS, 1994, p. 238)

A partir da análise das teorias de Pierre Bourdieu e Teresa de Lauretis aqui mobilizadas, percebemos que a noção de feminino remete já a um significado situado no centro das relações do sistema de gênero que, devido a sua permanência ao longo da história, tende a ser compreendido enquanto imutável, ignorando-se a capacidade produtiva do discurso. Ainda sobre esta problemática, vale recorrer, à concepção de gênero elaborada por Judith Butler.

A filósofa estadunidense pensa o gênero como, antes mesmo de uma construção social, uma construção discursiva que funcionaria enquanto "uma identidade tenuemente constituída no tempo, instituído num espaço externo por meio de uma repetição estilizada de atos" (BUTLER, 2015, p. 242, grifo da autora). O gênero, segundo ela, representa uma interpretação cultural de uma série de comportamentos repetidos que compõem o conjunto de produção no qual o sexo será reconhecido. Assim, Butler se opõe à noção do sistema sexo-gênero como uma mera oposição natureza/cultura:

Se o sexo é, ele próprio, uma categoria tomada em seu gênero, não faz sentido definir o gênero como a interpretação cultural do sexo. $O$ gênero não deve ser meramente concebido como a inscrição cultural de significado num sexo previamente dado (uma concepção jurídica); tem de designar também o aparato mesmo de produção mediante o qual os próprios sexos são estabelecidos. Resulta daí que o gênero não está para a cultura como o sexo para a natureza; ele também é o meio discursivo/cultural pelo qual "a natureza sexuada" ou "um sexo natural" é produzido e estabelecido como "pré-discursivo", anterior à cultura, uma superfície politicamente neutra sobre a qual age a cultura (BUTLER, 2015, p. 27, grifo da autora). 
Butler demonstra como a correlação entre sexo e gênero se dá através da linguagem, que não apenas descreve ou representa a realidade, mas também a constitui, de modo que o próprio corpo só é inteligível quando associado a um gênero - nesse ponto, a teoria de Butler radicaliza a proposição de De Lauretis. Como afirma Foucault (2014), os sistemas jurídicos de poder produzem os próprios sujeitos que em sequência representam, como é o caso da categoria "mulheres" acionada pelo feminismo. Tal produção se dá sempre dentro da própria matriz, porém, como afirma Butler:

Afirmar que o sujeito é autoproduzido em e como uma matriz generificada de relações não é desconsiderar o sujeito, mas apenas buscar pelas condições de sua emergência e operação. A "atividade" dessa generificação não pode, estritamente falando, ser um ato ou expressão humana, uma apropriação premeditada e certamente não é uma questão de colocar uma máscara; é a matriz através da qual todo querer se torna primeiro possível, sua condição cultural de possibilidade. Nesse sentido, a matriz de relações de gênero antecede a emergência do "humano" (BUTLER, 1993, p.7)

É importante ressaltar, igualmente, que, para Butler, a ilusão da substantivação do gênero faz com que ele seja compreendido como "constituinte dessa identidade que supostamente é" (BUTLER, 2015, p.56). Assim, o gênero é algo que "se faz" e não algo que "se é”, não havendo nenhuma relação necessária entre ele e o corpo. Sob essa perspectiva, o "feminino" seria uma ilusão de identidade determinante e determinada por atos repetidos, o que quebra a ideia também ilusória de um eu contínuo e total marcado pelo gênero. Butler não propõe, no entanto, uma ruptura completa com o gênero, mas sua subversão e transfiguração que deve se dar no interior do próprio discurso, explorando suas múltiplas possibilidades em um movimento de construção e desconstrução.

A partir de tais problemáticas, Butler (2015) também coloca em questão a unidade da categoria "mulheres", por considerá-la como uma forma de fixar e restringir os sujeitos que pretende libertar. Ao desconstruir essa categoria é possível também ressignificá-la, pois buscar romper com o essencialismo das identidades não torna impossível conceber a fixação parcial de identidades a partir de pontos comuns, mas apenas desacomodar as noções estáticas e binárias do sujeito que, na busca pela liberação de um grupo de indivíduos, acaba por aprisioná-lo a uma categoria supostamente fixa e imutável.

Um dos atributos pressupostos dentro da matriz heterossexual é a continuidade e coerência entre sexo/gênero/desejo. Assim, Butler também evidencia como esses corpos são concebidos, a priori, enquanto heterossexuais. Quer dizer, um sujeito compreendido culturalmente como fêmea será também feminino e apresentará um desejo natural e contínuo heterossexual, portanto, por sujeitos machos/masculinos. Os dispositivos e práticas reguladores do poder funcionam de modo a determinar uma identidade coerente que não desafie o sistema de gênero: 
Em outras palavras, a "coerência" e a "continuidade" da "pessoa" não são características lógicas ou analíticas da condição de pessoa, mas, ao contrário, normas de inteligibilidade socialmente instituídas e mantidas. Em sendo a "identidade" assegurada por conceitos estabilizadores de sexo, gênero e sexualidade, a própria noção de "pessoa" se veria questionada pela emergência cultural daqueles seres cujo gênero é "incoerente" ou "descontínuo", os quais parecem ser pessoas, mas não se conformam às normas de gênero da inteligibilidade cultural pelas quais as pessoas são definidas. (BUTLER, 2015, p. 43)

Considerando-se que as normas de gênero pressupõem, igualmente, normas de sexualidade, a mulher lésbica ou bissexual já apresenta um desafio para constituição inteligível de sua "identidade" por denunciar a ilusão de naturalidade da heterossexualidade. Opera-se também uma necessidade da estabilização do desejo, de modo que mesmo que se aceite o "anormal", aquele que não apresenta um desejo entendido como heterossexual, é cobrado dele uma continuidade das práticas de sua sexualidade para que possa ser afirmada sua legitimidade, não abrindo espaço para qualquer contingência. Ainda pensando com Judith Butler, os corpos que contestam a matriz heterossexual representam em si uma ameaça, pois

O que permanece "impensável" e "indizível" nos termos de uma forma cultural existente não é necessariamente o que é excluído da matriz de inteligibilidade presente no interior dessa forma; ao contrário, o marginalizado, e não o excluído, é que é a possibilidade cultural causadora de medo ou, no mínimo, da perda de sanções. Não ter o reconhecimento social como heterossexual efetivo é perder uma identidade social possível em troca de uma que é radicalmente menos sancionada. O "impensável" está assim plenamente dentro da cultura, mas é plenamente excluído da cultura dominante. (BUTLER, 2015, p. 138-139)

Sendo assim, a teórica destaca como não se trata de uma exclusão completa da matriz, mas da marginalização, necessária para a própria afirmação de uma cultura enquanto dominante, das formas de existência que não apresentam todos os atributos necessário para ser identificado enquanto "pessoa". Cabe ressaltar, igualmente, que as construções e estilizações operadas pelo gênero e sua imprediscibilidade na designação do sujeito geram consequências extremamente coercitivas e violentas quando contestadas.

Para se pensar a compulsoriedade da heterossexualidade, recorro também ao artigo de Adrienne Rich que critica o modo de grande parte da crítica feminista heterossexual de conceber a lésbica enquanto uma imagem espelhada da heterossexualidade ou, mesmo, da homossexualidade masculina, denunciando o caráter compulsório das sexualidades ditas "normais". Uma grande contribuição da autora está nas noções complementares de "existência lésbica" e "continuum lésbico" por ela propostas, a primeira remetendo "tanto ao fato da presença histórica de lésbicas 
quanto da nossa criação contínua do significado dessa mesma existência” (RICH, 2010, p. 35). O "continuum lésbico", por sua vez, se refere ao conjunto de experiências de identificação da mulher, ao longo de sua vida e através da história, manifestada por meio de diferentes vínculos e resistências, sendo a existência lésbica a marca da ruptura com o modo compulsório de vida, historicamente apagada e privada de uma tradição e de uma continuidade social.

Rich insiste sobre a posição política da lésbica, negada quando compreendida apenas em termos de uma "preferência sexual", propondo novas formas de compreensão tanto da posição de contestação dessas mulheres, quanto do erótico desses corpos. Apesar de as críticas, por ela sofridas, no que concerne a certo esvaziamento da importância do desejo na definição da lésbica enquanto uma categoria política - cujo debate não intento retomar neste trabalho -, o "continuum lésbico" proposto tem sua ênfase na necessidade da consolidação de uma tradição e um esteio para as mulheres que fuja ao modelo patriarcal, estabelecendo assim um discurso alternativo. Ela denuncia como a existência lésbica foi sistematicamente negligenciada em diferentes textos e aponta como uma das principais características da manutenção do poder masculino a negação da sexualidade nas mulheres, através de forças que fazem crer o casamento e a heterossexualidade como incontornáveis. Segundo ela, o controle da consciência feminina que leva a essa compulsoriedade se dá, sobretudo, através "[d]o apagamento da existência lésbica (exceto quando vista como exótica ou perversa) na arte, na literatura e no cinema e [d]a idealização do amor romântico e do casamento heterossexual” (RICH, 2010, p. 26). Tal noção de Rich se aproxima da noção de tecnologias sexuais de Foucault e, também, das tecnologias do gênero exploradas por De Lauretis. Isto posto, tanto o gênero como a sexualidade são representações que só fazem sentido num sistema relacional, construído, ao mesmo tempo, objetiva e subjetivamente. É possível, então, pensar a formação de um "continuum lésbico" na literatura e em outras formas de expressão enquanto discursos em posição de constante resistência, necessários para a própria sobrevivência dos indivíduos considerados dissidentes.

Se o poder tem também seu caráter produtor e a desconstrução do gênero inevitavelmente causa sua (re)construção, cabe questionarmos, como propõe De Lauretis, os termos em que se tem feito essa "des-reconstrução", pois o processo de (re)construção do gênero fora dos essencialismos só pode ocorrer através de um afastamento do referencial androcêntrico de sua (re)produção pelos discursos institucionais. A possibilidade dessas novas configurações das relações e suas representações se dá nos espaços que funcionam como o ponto cego desses mesmos discursos, um espaço não representado, mas implícito, onde o sujeito do feminismo pode existir enquanto esse sujeito em processo.

Tendo em vista essas considerações, proponho um olhar para a manifestação literária desse sujeito em andamento, recorrendo à terminologia empregada por De Lauretis para pensar como se articula esse space off na literatura. Desse modo, na próxima etapa, será discutido como a literatura pode vislumbrar esse sujeito nunca plenamente representado no discurso dominante, buscando formar uma tradição alternativa e transformar, conforme a proposição de Bourdieu, as categorias de entendimento "com as quais nós construímos o mundo (mas que, sendo oriundas desse mundo, estão por essência em acordo com ele, ainda que permaneçam despercebidas)" (BOURDIEU, 2014, p. 17). Trata-se de pensar a literatura escrita por mulheres através da 
possibilidade de uma conexão que ultrapasse as representações estáticas, realizando um movimento de reinscrição, reconstrução e ressignificação do que é concebido como possível em relação ao feminino e à sexualidade.

\section{Violette Leduc e a escrita de um "Assunto de meninas"}

No que concerne ao estudo das obras escritas por mulheres, é importante ressaltar que a particularidade de suas representações não se resume, como poderia se pensar, à recusa das narradoras e/ou personagens de se submeterem à ordem patriarcal, ou encontra aí seu potencial político máximo. Segundo Eurídice Figueiredo (2014), em artigo sobre a crítica feminista e a história das mulheres na literatura, também as protagonistas das obras escritas por homens no século XIX, como em Madame Bovary e Anna Karenina, se rebelaram contra a moral que repercute a dominação masculina, de modo que a questão que nos falta ainda responder é:

O que muda na construção das personagens femininas criadas por escritoras? Às vezes é difícil saber, sobretudo se se fizer uma leitura meramente do conteúdo. A análise de romances escritos por mulheres, nos últimos 50 anos, que se limitar a afirmar que as personagens não se submetem à ordem patriarcal não vai acrescentar nenhum diferencial, porque as protagonistas dos romances escritos por homens no século XIX também se rebelaram. É preciso ir além, buscando elucidar de que maneira as escritoras estão tratando, narrativa e esteticamente, assuntos que dizem respeito às figurações das mulheres. (FIGUEIREDO, 2014, p.32)

É preciso, desse modo, pensar a maneira pela qual se dá a contraposição do poder por essas mulheres e se tais narrativas revelam uma descentralização do discurso, ao abordarem assuntos tidos como proibidos e/ou serem produzidas por sujeitos marginalizados. Tendo em vista tais aspectos, proponho uma observação da subversão através da possibilidade de releitura dos atributos que constituem o sujeito mulher heterossexual, chamando a atenção para a pluralidade dos sujeitos agrupados dentro dessa categoria. Trata-se, desse modo, de procurar mostrar que não basta que o feminino ou a transgressão esteja no centro da narrativa, é necessário pensar com qual projeto político esses textos dialogam, para que se possa falar de uma escrita capaz desse movimento de ressignificação, denunciando também a violência da ilusão de universalidade contida tanto no apagamento da mulher, quanto na busca por defini-la de modo estabilizado dentro de um sistema marcado pela relação hierárquica, binária e normativa do gênero e dos corpos que eles supostamente identificam.

É sabido que, no campo da literatura, grande parte do cânone mundial é ainda dominado pelo masculino, assim como a crítica. Se recorrermos a célebre obra de Virginia Woolf, Um teto todo seu, publicada originalmente em 1929, que reflete, principalmente, sobre a literatura inglesa, vemos como a mulher só vai alcançar certo espaço na produção literária no século XIX. Woolf aponta, igualmente, que a mulher enquanto um tema apareceu recorrentemente na literatura dos 
diferentes séculos. Ela relaciona a ausência de uma literatura significativa escrita por mulheres até o século XIX com a dependência financeira que lhes foi imposta ao longo dos séculos. Em seu artigo "Profissões para mulheres", de 1941, a autora inglesa ultrapassa a questão financeira e aborda a necessidade de se matar o "Anjo do lar" que se coloca entre a mulher e o papel para que possam afirmar-se intelectualmente. Esse "anjo" é a mulher simpática, apaziguadora, altruísta, pura, meiga e desprovida de opiniões, essa que encarna tudo o que se espera do feminino e separou a mulher ao longo da história do "racional". Porém, resta ainda uma pergunta que ainda estamos lutando para responder: "o Anjo morreu, e o que ficou?", o que leva a outra questão, "Quer dizer, o que é uma mulher? Juro que não sei. E duvido que vocês saibam. Duvido que alguém possa saber, enquanto ela não se expressar em todas as artes e profissões abertas às capacidades humanas" (WOOLF, 2016, p. 14).

Seguindo a direção desse questionamento infindável que proponho que pensemos a obra de Leduc e a escrita da sexualidade pelas mulheres, não para responder o que é a mulher ou a sua sexualidade, mas para pensar as múltiplas possibilidades desses termos. As mulheres ainda estão lutando para se expressar plenamente, e essa expressão, como nos mostra os pontos ressaltados por Bourdieu, De Lauretis, Butler e Rich, acontece dentro de um sistema de gênero que constrói e é construído por categorias que são elas mesmas formas de prisões, de modo que as narrativas, para desafiar a ordem e construir pela literatura esse outro espaço, precisam operar mais que um movimento de subversão das personagens ou temática, oferecendo meios para reinscrição das mulheres em sua pluralidade. O foco na obra de Leduc se justifica por colocar em cena a escrita do corpo da mulher que não se curva diante do olhar masculino, uma escrita da descoberta da sexualidade e do corpo em usos e modos que se afastam do paradigma dominante do prazer puramente genital, representando uma obra ainda atual nessas figurações e uma voz inovadora na escrita da lesbianidade. Em suas obras, que apresentam um forte cunho autobiográfico, não sendo bem delimitada a linha entre ficção e realidade mesmo nos textos que não são autobiografias declaradas, a autora se apresenta muitas vezes distante do modelo de feminilidade, aproximando-se do considerado enquanto masculino.

Thérèse et Isabelle foi publicada oficialmente em 1966, porém a narrativa era, originalmente, parte de Ravages (1955). A protagonista Thérèse (primeiro nome civil de Leduc), no texto original de Ravages, narra os diferentes momentos de sua vida amorosa, desde a descoberta e o compartilhamento da sexualidade no colégio com Isabelle, sucedida por sua relação com Cécile e depois com Marc, com quem vem a se casar, culminando em seu aborto clandestino que quase a leva à morte. Apesar de a obra ter sido publicada em 1955, a parte inicial foi suprimida pelo editor que a considerou escandalosa e obscena por tratar do encontro amoroso e sexual entre duas estudantes, de modo não puramente afetiva, mas também fortemente erótico. A censura dessa primeira parte é motivo de grande dor e decepção por parte de Leduc, que considera o ato enquanto um assassinato. Em Thérèse et Isabelle, Leduc escreve com grande liberdade e sem manifestar qualquer culpa pelo o que é narrado ou pelo ato de narrar. Apesar de sua escrita ser direta, realista e sem pudores, é também poética, escrevendo com uma liberdade não antes observada nas escritas de mulheres, associando liricamente extremos o que, para Catherine Viollet (1995), leva a um texto absolutamente novo e belo, cujo pioneirismo não foi ainda completamente explorado. 
Para além da exposição da sexualidade ou mesmo do corpo da mulher, o que já estava presente em Sade, a obscenidade atribuída ao texto é, provavelmente, devida ao fato de se centrar sobre formas alternativas de desejo e relação com o próprio corpo, que não se encontram inscritas no modelo dominante, ao não estarem de acordo com o paradigma heterossexual. Como pontuou Rich (2010), a representação de qualquer forma de heterossexualidade, mesmo quando requer o uso da força e anula o sujeito mulher, é sexualmente mais "normal" do que a sensualidade entre mulheres, tida como "doentia" e, mesmo pornográfica. Considerando-se que o vocábulo latino obscenus significa, originalmente, "mau agouro", tal dimensão atribuída ao texto em questão é pertinente apenas se levarmos em conta que ele representa um "mau agouro", uma "ameaça", para o funcionamento regular da matriz heterossexual. As personagens, Thérèse e Isabelle, apesar de jovens estudantes, são retratadas em uma relação de interação real entre dois corpos que parecem se bastar. Leduc não aborda na narrativa questões relacionadas ao questionamento das personagens sobre a própria sexualidade, tampouco lhes atribui alguma culpa ou remorso por seus atos. Diferentemente de outras narrativas do século XX que abordam a relação sáfica entre colegiais, como o filme Olivia de Jacqueline Audry, de 1951, sobre o romance homônimo de 1949, ou de Senhoritas de uniforme (1931), adaptação da obra de Christa Winsloe e de final trágico, a obra de Leduc não trata da sexualidade de modo somente alusivo ou fica estritamente no plano sentimental.

A obra, em sua publicação separada, não possui grandes acontecimentos exteriores, sendo o próprio acontecimento o corpo de duas moças se entregando uma a outra. A narrativa começa com a descrição do colégio por Thérèse, seguida da aparição de Isabelle, primeiramente, manifestando um sentimento de raiva, que pode ser pensado já como um indício da tensão do desejo. Isabelle uma noite vai ao leito de Thérèse e a convida para o seu, quando começam a se envolver. Apesar de rondar a narrativa a possibilidade de descoberta por alguma inspetora do colégio, o que nunca realmente se realiza, e da mãe de Thérèse a retirar do colégio, o próprio clímax é a tensão entre a proibição, o desejo e o nascimento de um amor que ambas precisam ainda aprender como lidar. Como no primeiro encontro amoroso, interrompido pelo receio de serem percebidas pela inspetora da noite:

Isabelle me puxou para trás, deitou-me embaixo do edredom, levantoume, segurou-me em seus braços: tirava-me de um mundo onde eu não vivera para me lançar em um mundo onde não vivia ainda; os lábios entreabriram os meus, molhavam os dentes que eu serrava. A língua muito carnuda me assustava: o sexo estranho não entrou. Eu esperava ausente e recolhida. Os lábios passeavam sobre os meus lábios: pétalas me espanavam. Meu coração batia muito alto e queria escutar esse selo de doçura, essa fricção nova. Isabelle me beija, eu me dizia. Ela traçava um círculo ao redor de minha boca, cercava a excitação, dava um beijo fresco em cada canto, dispunha duas notas soltas, voltava, hibernava. Meus olhos estavam grandes de espanto sob minhas pálpebras, o rumor das conchas muito intenso. Isabelle continuou: descíamos, nó após nó em uma noite além da noite no colégio, além da noite da cidade, além da noite do 
depósito dos bondes. Ela fizera seu mel sobre meus lábios, as esfinges voltaram a dormir. Soube que fora privada dela antes de encontrá-la. Ela escutava o que me dava, beijava o vapor embaçado sobre um vidro. Isabelle recolocou seus cabelos sob os quais tivemos um abrigo. (LEDUC, 2000 , p. 23-24)

O envolvimento se dá num passo a passo que aos poucos vai se tornando um todo, como uma partitura musical - contendo mesmo uma alusão direta à música com as "notas soltas". A escrita de Leduc, ainda que seja precisa e não se deixe dissimular por pudores, é também sedutora e elegante, evocando diferentes imagens e retomando aspectos que atribuem realidade e sensualidade ao ato, usando também da ambiguidade na repetição da palavra "lábios".

Apesar de aludirem constantemente ao medo de serem percebidas, de modo que as inspetoras representam uma ameaça iminente que pode ser associada aos dispositivos de controle do poder, o momento da repreensão nunca realmente acontece, como se ambas tivessem encontrado um modo de emergir nas brechas do sistema, em um espaço que lhes é próprio, "além da noite do colégio e além da noite da cidade":

Eu lhe fazia perguntas, exigia apenas o silêncio. Entoávamos, nos queixávamos, revelávamo-nos atrizes inatas. Abraçávamo-nos até sufocar. Nossas mãos tremiam, nossos olhos se fechavam. Parávamos, recomeçávamos. Nossos braços recaíam, nossa pobreza nos deliciava. Eu modelava seu ombro, queria para ela carinhos camponeses, desejava sob minha mão um ombro agitado, uma casca. Ela fechava meu punho, alisava uma pedra. A ternura me cegava. Frente a frente dizíamos duramente não. Abraçávamo-nos pela última vez depois de uma última vez, reuníamos dois troncos de árvore em um só, éramos os primeiros e os últimos amantes como nós somos os primeiros e os últimos mortais quando descobrimos a morte. Os gritos, os rugidos, os barulhos das conversas no pátio vinham em ondas. (LEDUC, 2000, p. 42)

As duas parecem ser situadas em um tempo fora do tempo, um espaço separado daquele do colégio e da vida "normal", estabelecendo-se uma temporalidade única e contínua, um abraço último que sempre se repete, uma união de dois corpos que apesar de não completamente impermeável ao mundo exterior a eles, uma vez que o barulho chega em ondas, se mantém em um outro lugar onde é possível essa interação até quase a extenuação delas mesmas, em uma completa fusão: "Ela me refletia, eu a refletia: dois espelhos se amam" (LEDUC, 2000, p. 137).

Muitas vezes traduzido pela ameaça da inspetora chegar está o medo de Thérèse da separação sempre prestes a acontecer, como "uma orgia de perigos" (LEDUC, 2000, p. 64) 6 , tornando o amor a perseguição de uma satisfação impossível para qual ela não consegue deixar de se entregar. Assim como Thérèse se entrega ao amor, Leduc se entrega a sua escrita, em descrições longas e imagéticas do ato amoroso: 
A mão despiu meu braço, parou perto da curva, ao redor de onde pulsa o sangue, fornicou nos desenhos, desceu até o pulso, até a ponta das unhas, revestiu meu braço com uma longa luva de couro, caiu do meu ombro como um inseto, se agarrou à axila, esfregou o tufo de pelos. Eu estendia meu rosto, escutava o que meu braço respondia a aventureira. A mão querendo-se conquistadora colocava no mundo meu braço, minha axila. A mão passeava sobre o balbucio dos arbustos brancos, sobre as últimas geadas das pradarias, sobre a espessura dos primeiros brotos. A primavera que gritava de impaciência na minha pele explodia em linhas, em curvas, círculos. Isabelle estirada sobre a noite embalava meus pés, desenrolava as faixas da dúvida. As mãos abertas sobre o colchão, eu fazia o mesmo trabalho de charme que ela. Ela abraçava o que havia acarinhado em seguida, com sua mão leve, despenteava e espanava com as plumas da perversidade. O polvo nas minhas entranhas estremecia, Isabelle bebia no seio direito, no seio esquerdo. Eu bebia com ela, enchia-me de trevas quando sua boca se afastava. Os dedos voltavam, circundavam, mediam o calor do seio, os dedos terminavam no meu ventre em destroços hipócritas. Um mundo de escravos que tinham o mesmo rosto de Isabelle renovavam minha fronte, minhas mãos. (LEDUC, 2000, p. 67)

O que interessa observar no fragmento destacado é o modo como a sexualidade descrita na obra excede um desejo apenas genital, estando focada também em diferentes carinhos. Todo o corpo é acionado na narrativa e colocado a serviço do prazer, do amor e da descoberta. A representação corporalidade se aproxima de uma retomada do "perverso poliformo", ao colocar em cenas corpos que, apesar da ação dos aparatos reguladores do poder, agem de modo a reconstruir seus usos legítimos, reinserindo no universo do pensável e do fazível aquilo que Bourdieu afirma ter sido excluído para que se possa garantir o pertencimento a um gênero. Nos diferentes encontros vão sendo narradas as interações cada vez mais íntimas de seus corpos, passando pelo momento da penetração e da união: "Escutava em seus dedos o que lhe cantavam os meus" (LEDUC, 2010, p. 137) ${ }^{8}$. A narradora leduciana descreve a relação como o desejo de uma se tornar a outra, em uma completude na qual se bastariam, percebendo a própria virilidade e capacidade de sentir prazer em um corpo de mulher, como quando remete à descoberta do clitóris: "Eu descobriria o pequeno sexo viril que temos" (LEDUC, 2010, p. 96).

Essa presença do considerado "impensável" é manifestado não só no modo como a corporalidade aparece em Thérèse et Isabelle. Na narrativa de Ravages, pode ser percebido que a sexualidade e mesmo o acordo com a performance atribuída ao gênero feminino não se apresentam de modo contínuo. A personagem-narradora se envolve ainda com outra mulher e outro homem, que se refere a ela através de apelidos no masculino. Isto posto, é possível dizer que a obra representa uma manifestação desse excesso recalcado do gênero que pode irromper dentro do sistema e ameaça sua estabilidade.

O universo do colégio interno para meninas já foi e continua sendo muito explorado pelo 
cinema e pela literatura para retratar esse espaço de moças convivendo com outras moças quase que exclusivamente, em uma idade importante para sua autofundação identitária. Tomo como exemplo aqui o filme canadense Lost and delirious (2001), adaptação da obra The waves of the bath (1993) de Susan Swan dirigida por Léa Pool que recebeu no Brasil o título "Assunto de meninas". A trama se passa no colégio para o qual Mouse, apelido de Mary, é enviada pelo pai e a madrasta após a morte da mãe. Mary é alojada no dormitório de Tory (Victoria) e Paulie, e percebe desde logo a interação diferenciada das duas, chegando a vê-las compartilhar a cama nuas e ouvir gemidos durante a noite. Victoria e Paulie são representadas em um laço ambíguo, não é estabelecido verbalmente uma relação e, tampouco, se identificam enquanto lésbicas. Porém, o envolvimento é patente, interrompido apenas quando a irmã mais nova de Tory entra no quarto uma manhã e flagra as duas nuas na cama, momento em que Tory se sente interpelada e decide se distanciar de Paulie, afirmando sua suposta heterossexualidade ao se aproximar de Jack, um rapaz do colégio interno próximo. O receio de que sua irmã revele para os seus pais a cena parece ser a representação da ameaça da lei que age de modo a excluir as formas sexuais e corporais que não devem ser compreendidas como possíveis. O medo age em Tory de modo a forçá-la a entrar na sociedade, aceitando sua mediação, enquanto Paulie escolhe a resistência. Ela sofre intensamente com o afastamento, aproximando-se progressivamente do falcão ferido que encontraram em uma corrida no bosque próximo ao colégio. Decide, então, cuidar dele, manifestando uma relação de profunda interação e aprendendo a se comunicar com ele para ensiná-lo a voar novamente. Em diferentes momentos do filme, Paulie é retratada correndo com os braços abertos em direção ao bosque, adentrando em meio às árvores em um movimento que parece manifestar um desejo de incorporação nesse outro espaço.

Na obra Teoria King Kong (2016) também é abordada a presença de uma figura que se associa ao animal em uma relação de identificação com a mulher. Virginie Despentes explora, na parte "King Kong Girl", a relação entre o feminismo e King Kong na versão de Peter Jackson do longametragem. No filme, a protagonista loira é oferecida como sacrifício a King Kong - ser que não é retratado com nenhum atributo ou em nenhuma cena que permita lhe atribuir um gênero porém acabam gerando um laço de proteção e sensualidade que escapa ao sexual. O título dessa parte pode ser compreendido enquanto a possibilidade de King Kong ser uma garota, que redimensiona o significado do termo por não ter nada que indique sua feminilidade. A criatura habita uma ilha fora do mapa, para onde a atriz é levada por um diretor megalomaníaco para uma filmagem, ocupada por outras criaturas que também não são machos ou fêmeas:

King Kong funciona, aqui, como uma sexualidade que precede a distinção de gêneros tal como politicamente imposta no final do século XIX. King Kong encontra-se além da fêmea e do macho. Esse ser está na encruzilhada entre o homem e o animal, o adulto e a criança, o bom e o mau, o primitivo e o civilizado, o branco e o preto. Híbrido, diante da obrigatoriedade do binário. A ilha do filme é a possibilidade de uma sexualidade polimorfa e superpoderosa. Aquilo que o cinema deseja capturar, exibir, desnaturalizar e depois exterminar. (DESPENTES, 2016, p. 94) 
Despentes interpreta a escolha da mulher loira por seguir o homem que vem salvá-la da criatura e capturar o animal como uma escolha pela heterossexualidade e pela vida urbana que sacrifica o que nela há de selvagem e potente, atribuindo ao longa a função de metáfora da dominação que impõe o paradigma binário e hierárquico, entre o masculino e o feminino, a mente e o corpo, o racional e o emocional etc. King Kong aparece no livro como a possibilidade de pensar o mundo com novas configurações e relações que fogem ao paradigma heterossexual, masculino e, mesmo, puramente humano, em que a garota King Kong poderia existir mesmo sem as marcas historicamente atribuídas ao gênero, o que nos remete ao pensamento de Wittig sobre as categorias sexuais enquanto construções políticas.

Enquanto Tory pode ser aproximada da loira que escolhe a heterossexualidade, o falcão, que também não possui um sexo definido na narrativa do filme, pode ser compreendido da mesma forma que Despente propõe que pensemos King Kong. O bosque para o qual Paulie corre repetidamente, igualmente, se aproxima desse outro espaço em que ela ocupa um lugar entre o humano e o animal, como se fosse uma extensão do falcão e ele dela. $\mathrm{O}$ animal, que Paulie encontra justo no dia em que Tory conhece Jack, parece o símbolo dessa vida fora do mundo civilizado, porém afetada por ele e o laço entre eles foge ao inteligível dentro do pensamento racional da filosofia ocidental que separa claramente o humano e o animal, o feminino e o masculino, a mente e o corpo. Desse modo, a relação quase simbiótica que estabelecem representa a contestação operada por Paulie, preferindo se afastar do mundo da dominação masculina e estabelecer um vínculo com a ave, ajudando-a a recuperar seu voo, ao invés de escolher a heterossexualidade.

Impedida de viver seu amor, Paulie busca se fundir ao falcão no bosque, culminando no final trágico, no qual é sugerido que ela se atira do alto do colégio enquanto as outras alunas a observam debaixo e o falcão alça seu voo derradeiro para além dali, além do colégio e da censura. A câmera se fixa no corpo de Paulie ameaçando cair e depois apenas no voo da ave, o que mais uma vez sugere a relação fusional entre as duas. Apesar de tratar do amor entre meninas e da sexualidade com cenas bem insinuantes, o filme, no entanto, apresenta ainda alguns aspectos comuns às narrativas lésbicas, ou, como vimos, às narrativas escritas por homens sobre mulheres transgressoras: a personagem que não aceita a ordem patriarcal é punida com a morte. Nesse ponto, a obra de Leduc é ainda mais contemporânea e transgressora, pois as duas jovens amantes se separam apenas por conta do acaso, quando a mãe de Thérèse a retira do colégio, nada tendo a ver com uma punição devido à relação das duas. Mesmo que o filme de 2001 mostre a possibilidade de relações que ultrapassam o limite do humano, ele se insere ainda na tradição que passa uma mensagem para as mulheres: se você não for como Tory e recusar a expulsar aquilo que te faz uma "pessoa incoerente", você será punida. Por essas razões, Thérèse et Isabelle se apresenta ainda como uma narrativa que precisa ser explorada e pensada como esse discurso que não está totalmente fora da cultura dominante, mas que encontra um modo de resistir apesar dela e operar uma (re)inscrição do corpo da mulher que não está a serviço do masculino. 


\section{Consideraçẽes finais}

A obra literária aqui estudada é uma narrativa que ressignifica as noções estáticas do desejo, pensado de modo alternativo, a partir de um corpo todo atravessado por vivências e prazeres a serem explorados. Leduc descreve uma experiência que foge à mediação heteronormativa, o que opera como um modo de burlar os construtos que passam a ilusão da continuidade do sujeito. Tal movimento também se apresenta enquanto um modo de (re)construir o gênero, ampliando as fronteiras do que significa ser mulher e ser uma mulher que ama e sente prazer com outras mulheres. Destarte, é possível observar a emergência desse sujeito do feminismo em andamento pensado por Teresa de Lauretis, que busca subverter o sistema para (re)inscrever outras possibilidades afetivas e corporais, e também a possibilidade de uma importante tradição alternativa nas narrativas de mulheres, compondo o "continuum lésbico" proposto por Rich, no qual vão se construindo discursos alternativos que narram e fazem existir esses sujeitos que a matriz heterossexual insiste em marginalizar e invisibilizar. A obra representa uma produção crucial para esse continuum na literatura, pois ainda que não seja a primeira a abordar a sexualidade entre mulheres ou a mais explicita, compara-se com narrativas mais recentes, é um texto potente em seu lirismo e em sua transgressão, recusando-se a se dissimular para agradar o poder masculino. Desse modo, o que importou aqui pensar não é se essa é uma literatura feminina, mas de que modo ela se articula enquanto feminista, em um feminismo que contesta a doxa por ele mesmo incorporada e aceita que mulheres é um termo plural.

O objetivo nessa análise foi, portanto, apontar que se o gênero e a sexualidade são produzidos conjuntamente, um discurso que reafirma a mulher enquanto oposta e inevitavelmente desejante do homem, sem nenhuma pretensão de subversão ou releitura do feminino, ainda que fale da lésbica ou de uma personagem transgressora, não estará propondo novas configurações que tensionem o sistema de gênero. Para tal, são necessárias narrativas das quais o sujeito do feminismo possa emergir. É desse espaço que a obra de Leduc e outras autoras e teóricas falam, um outro lugar que só pode existir em posição de contradição, considerando que falamos sempre de dentro desse sistema, mas podendo desafiá-lo. Trata-se de uma tensão constante que denuncia o caráter arbitrário da ilusão de naturalidade sem, no entanto, propor a utopia da abolição total dos gêneros ou das múltiplas sexualidades, pois, como coloca Butler, se os gêneros, assim como a heterossexualidade, não são verdadeiros ou falsos, originais ou derivados, podem, como portadores desses atributos criados mediante performances sociais, tonar-se "completa e radicalmente incriveis" (BUTLER, 2015, p.244) e a zona da literatura é um espaço em que tais possibilidades são já operáveis.

\section{notas}

1 "refers to those individual or group actions deemed significant within a particular social or institutional setting."

2 De Lauretis toma emprestada a terminologia do cinema de um extracampo, que pode ser pensado como o espaço fora da cena mas implícita nela, seu extra-espaço que mesmo que invisível e "fora" dela, nela incide. 3 As traduções aqui presentes são de minha responsabilidade: "To claim that the subject is itself produced 
in and as gendered matrix of relations is not to do away with subject, but only to ask after the conditions of its emergence and operation. The "activity" of this gendering cannot, strictly speaking, be a human act or expression, a willful appropriation, and it is certainly not a question of taking a mask; it is the matrix through which all willing first becomes possible, its enabling cultural condition. In this sense the matrix of gender relations is prior to the emergence of the "human".

4 « Isabelle me tira en arrière, elle me coucha en travers de l'édredon, elle me souleva, elle me garda dans ses bras: elle me sortait d'un monde où je n'avais pas vécu pour me lancer dans un monde où je ne vivais pas encore; les lèvres entrouvrirent les miennes, mouillèrent mes dents que je serrais. La langue trop charnue m'effraya: le sexe étrange n'entra pas. J'attendais absente et recueillie. Les lèvres se promenaient sur mes lèvres : des pétales m'époussetaient. Mon cœur battait trop haut et je voulais écouter ce scellé de douceur, ce frôlement neuf. Isabelle m'embrasse, me disais-je. Elle traçait un cercle autour de ma bouche, elle encerclait le trouble, elle mettait un baiser frais dans chaque coin, elle déposait deux notes piquées, elle revenait, elle hivernait. Mes yeux étaient gros d'étonnement sous mes paupières, la rumeur des coquillages trop vaste. Isabelle continua: nous descendions nœud apràs nœud dans une nuit au-delà dela nuit du collège, au de-là de la nuit de la ville, au delè de la nuit du dépôt des tramways. Elle avait fait son miel sur mes lèvres, les sphinx s'étaient rendormis. J'ai su que j’avais été privée d'elle avant de la rencontrer. Elle écoutait ce qu'elle me donnait, elle embrassait de la buée sur une vitre. Isabelle renvoya sa chevelure sous laquelle nous avions eu un abri. »

5 «Je lui posais des questions, je n'éxigeais que du silence. Nous psalmodiions, nous nous plaignions, nous nous révélions des comédiennes innées. Nous nous serrions jusqu'à l'étouffement. Nos mains tremblaient, nos yeux se fermaient. Nous cessions, nous recommencions. Nos bras retombaient, notre pauvreté nous émerveillait. Je modelais son épaule, je voulais pour elle des caresses campagnardes, je désirais sous ma main une épaule houleuse, une écorce. Elle fermait mon poing, elle lissait un galet. La tendresse m'aveuglait. Front contre front nous nous disions non. Nous nous serrions pour la dernière fois après une dernière fois, nous réunissions deux troncs d'arbres en un seul, nous étions les premiers et les derniers amants comme nous sommes les premiers et les derniers mortels quand nous découvrons la mort. Les cris, les rugissements, le bruit des conversations dans la cour venaient par vagues. »

6 « une orgie de dangers »

7 « La main déshabilla mon bras, s'arrêta près de la veine, autour de la saignée, forniqua dans les dessins, descendit jusqu'au poignet, jusqu'au bout des ongles, rhabilla mon bras avec un long gant suédé, tomba de mon épaule comme un insecte, s'accrocha à l'aisselle. Je tendais mon visage, j'écoutais ce que mon bras répondait à l'aventurière. La main qui se voulait convaincante mettait au monde mon bras, mon aisselle. La main se promenait sur le babil des buissons blancs, sur les derniers frimas des prairies, sur l'empois des premiers bourgeons. Le printemps qui avait pépié d'impatience dans ma peau éclatait en lignes, en courbes, en rondeurs. Isabelle allongée sur la nuit enrubannait mes pieds, déroulait la bandelette du trouble. Les mains à plat sur le matelas, je faisais le même travail de charme qu'elle. Elle embrassait ce qu'elle avait caressé puis, de sa main légère, elle ébouriffait, elle époussetait avec le plumeau de la perversité. La pieuvre dans mes entrailles frémissait. Isabelle buvait au sein droit, au sein gauche. Je buvais avec elle, je m'allaitais de ténèbres quand sa bouche s'éloignait. Les doigts revenaient, encerclaient, soupesaient la tiédeur du sein, les doigts finissaient dans mon ventre en épaves hypocrites. Un monde d'esclaves qui avaient même visage que celui d'Isabelle éventaient mon front, mes mains. »

8 «J'écoutais dans ses doigts ce que lui chantaient mês doigts »

9 « Je découvrais le pétit sexe viril que nous avons » 


\section{Referencias}

BEAUVOIR, Simone. Le deuxième sexe. Paris: Gallimard, 2014

BOURDIEU, Pierre. La domination masculine. Paris: Seuil, 2014.

BUTLER, Judith. Bodies That Matter. Nova Iorque: Routledge, 1993

BUTLER, Judith. Problemas de Gênero: Feminismo e subversão da identidade. Rio de Janeiro: Civilização Brasileira, 2015.

DE LAURETIS, Teresa. A tecnologia do gênero. In: HOLLANDA, Heloísa Buarque (Org.), Tendências e impasses: O feminismo como crítica da cultura (pp.206-242). Rio de Janeiro: Rocco.

DESPENTES, Virginie. Teoria King Kong. São Paulo:n-1 edições, 2016.

FIGUEIREDO, Eurídice. História literária e crítica feminista: figurações das mulheres. In: SILVA, Antônio de Pádua Dias da. Memórias da Borborema 3. Feminismo, estudos de gênero e homoerotismo. Campina Grande (PB): Abralic, 2014. p. 27-46

FOUCAULT, Michel. A História da sexualidade I: A vontade de saber. Trad Maria Tereza da Costa Albuquerque e J. A. Guilhon Albuquerque2 Rio de Janeiro/São Paulo: Paz\&Terra, 2014.

LEDUC, Violette. Thérèse et Isabelle. Paris: Gallimard folio, 2000.

LOST and Delirius. Direção: Léa Pool. Produção: Lorraine Richard, Greg dummett, LouisPhilippe Rochon. Lions Gate Entertainment, 2001, 1 DVD.

MANN, Patrícia S. Micro-politics: agency in a postfeminist era. Minnesota: University of Minnesota Press, 1994

RICH, Adrienne. Heterossexualidade compulsória e existência lésbica. Bagoas: estudos gays, gêneros e sexualidades. Natal: v. 4, n. 5, jan./jun. 2010, p. 17-44.

SALIH, Sara. Judith Butler e a Teoria Queer. Belo Horizonte: Autêntica editora, 2015.

STREY, Mariene Neves. Gênero. In: JACQUES, Maria da Graça Correia; STREY, Mariene Neves; BERNARDES, Nara Maria Gazzeli; GUARESCHI, Pedrinho Arcides; CARLOS, Sérgio Antônio \& FONSECA, Tânia Mara Gali (Orgs.). Psicologia social contemporânea: Livro-texto (pp.181-198). Petrópolis: Vozes, 1998.

SWAN, Susan. The wives of the bath. Toronto: Knopf, 1993.

VIOLLET, Cathérine. «Violette Leduc : écriture et sexualité ». Tangence, n 47, 1995, p. 69-83. Disponível em: http://id.erudit.org/iderudit/025852ar Acesso em: 10 out 2017

WITTIG, Monique. The straight mind and other essays. Boston: Beacon Press, 1976.

WOOLF, Virginia. Um teto todo seu. Trad. Vera Ribeiro. Rio de Janeiro: Nova Fronteira, 1985.

WOOLF, Virginia. Profissões para mulheres e outros artigos feministas. Trad. Denise Bottmann. Porto Alegre: L\&PM, 2016. 